\title{
Small changes can make the difference
}

\section{Angeles Blanco ${ }^{1}$ • Juan García ${ }^{1}$}

Published online: 17 January 2020

(C) Springer-Verlag GmbH Germany, part of Springer Nature 2019

The 10th World Congress of Chemical Engineering (WCCE10) held in Barcelona, Spain, was a great success due to its multidisciplinary approach to cover all areas of chemical engineering. It was organized as the sum of scientific events and in parallel with Expoquimia, one of the most important trade fairs in Europe. The opportunities of attending general sessions and specific events in a close contact with industrial partners were a functional layout that marked the difference of this WCCE10.

As we all know, our planet is under a high stress from different points of view including resources and pollution. In an increasing world population, innovative chemical engineering approaches are continuously extending the limits of the resources at the same time that environmental impacts have been highly reduced. Although many successful approaches and concepts have been already developed and implemented, there is still a high potential to improve industrial processes in order to solve societal future challenges. The WCCE10 program brought innovative solutions to respond to major societal challenges which include environmental issues. Accordingly, a special issue on this topic is edited.

This special issue collects 7 papers dealing with improving existing treatments to extend their limits to favour the removal of contaminants. According to the philosophy of the congress of the added value of sum efforts, these papers were selected as examples of how marginal improvements can contribute to solve the challenges. To achieve this aim, special attention must be given to assure that the industry is also aware of these marginal improvements since by $\sum$ results big improvements can be obtained.

Authors and reviewers are greatly acknowledged for their contributions.

Responsible editor: Philippe Garrigues

Angeles Blanco

ablanco@ucm.es

1 Department of Chemical Engineering and Materials, Faculty of Chemistry, Complutense University of Madrid, 28040 Madrid, Spain

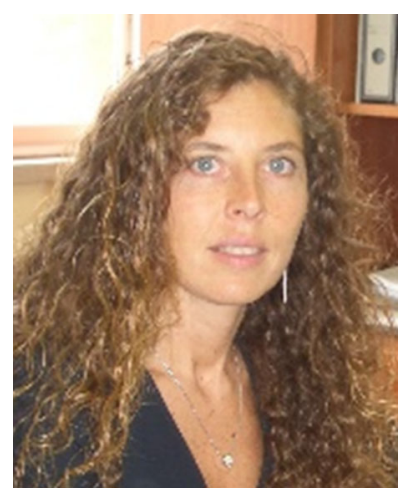

Angeles Blanco Scientific Secretariat WCCE10.

Dr. Blanco is a full professor in chemical engineering in the Chemical Engineering and Materials Department of the Complutense University of Madrid. Since 1990, she has worked on the development of sustainable processes considering circular economy and industrial symbiosis. She has a wide experience in the field of wastewater reclamation, closure of water circuits, waterfit-for-use and minimization of industrial wastes. Her works are developed in two parallel lines, one fundamental to generate new knowledge, and one applied to apply this knowledge to solve industrial challenges. She has published over 160 scientific publications (h-index 39); she has participated in 21 European projects and in 60 industrial projects of knowledge transfer and she has supervised 17 $\mathrm{PhD}$ students. Her current interest is on extending the limits of water reclamation, industrial symbiosis and characterization and application of new nanocellulose materials.

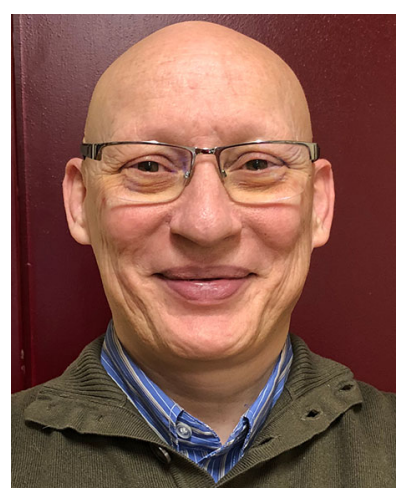

Juan García Dr. Garcia is a full professor in Chemical Engineering in the Chemical Engineering and Materials Department of Complutense University of Madrid. He has a wide experience in the catalysis and adsorption field, who has coauthored more than 100 publications and book chapters on this subject (h-index 31), and he has also supervised five $\mathrm{PhD}$ theses and three more in progress. Specifically, his research interests include the design of a wide range of materials, including carbon materials, mesoporous materials and metalcontaining nanoparticles. He has worked on the synthesis, characterization and applications of different forms of carbon materials and on the experimental study of catalytic systems and adsorption equilibrium and kinetics in fixed bed column. He has also led several projects with public and private funding about the wastewater and sludge treatment by catalytic processes and adsorption. 